\title{
EVALUATING BUSINESS-TO-BUSINESS M-COMMERCE IN SMES BY USING MCDM APPROACH
}

\author{
Ming-Tsang Lu* \\ Graduate Institute of Management Science \\ National Chiao Tung University \\ Hsinchu, Taiwan \\ E-mail: mingtsang.lu@gmail.com \\ Gwo-Hshiung Tzeng \\ Institute of Project Management \\ Kainan University \\ Luchu, Taoyuan, Taiwan \\ E-mail: ghtzeng@mail.knu.edu.tw \\ Shu-Kung $\mathrm{Hu}$ \\ Department of Business and Entrepreneurial Management \\ Kainan University \\ Luchu, Taoyuan, Taiwan \\ E-mail: syokou@mail.knu.edu.tw \\ Yung-Chang-Lin \\ Institute of Project Management \\ Kainan University \\ Luchu, Taoyuan, Taiwan \\ E-mail: nike.man@msa.hinet.net
}

\begin{abstract}
The invention and use of mobile commerce (m-commerce) technology have progressed tremendously in recent years. In small to medium-sized enterprises (SMEs), the decision of business-to-business (b2b) mcommerce is a multi-criterion decision analysis problem which involves both qualitative and quantitative factors, and its evaluation may be based on imprecise information or uncertain data. Furthermore, there can be significant dependences or important feedbacks among different levels of criteria or alternatives. However, most conventional decision models cannot capture these complex interrelationships. In this study, we present the use of a multi-attribute decision model which combined with Decision Making Trial and Evaluation Laboratory (DEMATEL) technique DANP (DEMATEL-based ANP) and VIKOR to identification of core factors in the decision of business-to-business m-commerce in SMEs. The decision network proposed in this study provides managers or planners a generalized evaluation framework for business-to-business m-commerce technological advances and adoptions. Findings from our multicriterion decision model also have important implications for developing b2b m-commerce applications in SMEs.
\end{abstract}

Keywords: mobile commerce, small to medium-sized enterprises (SMEs), business-to-business (b2b), decision making trial and evaluation laboratory (DEMATEL), DANP (DEMATEL-based ANP), VIKOR.

\footnotetext{
${ }^{*}$ Corresponding author
} 


\section{Introduction}

This study contributes in small to medium-sized enterprises (SMEs) in three ways. First, the adoption of business to business (b2b) mobile commerce (m-commerce) is explored from a multi-faceted perspective including technology, organization and environment. This implies that SMEs managers should consider these three factors before employing m-commerce. Second, the current study shows the relative importance of TOE framework in the decision to adopt mobile commerce. That is, administrators who are confident with mobile devices are likely to adopt $b 2 b$ mobile commerce. Hence, managers need to think about the basic functions and applications of $\mathrm{b} 2 \mathrm{~b}$ mobile commerce technologies. Lastly, the current findings reveal that usefulness and ease of use affect managers' strategy for adopting mobile commerce. Thus, to facilitate the acceptance of mobile commerce, the e-business environment should be perceived as useful and easy to use. A better understanding of the process of $b 2 b$ mobile commerce adoption will help researchers and decision makers' work together to implement proper strategies for mobile commerce.

Most of the conventional multi-criteria decision analysis (MCDA) models cannot handle the analysis of complex relationships among different hierarchical levels of criteria. Yet the decision to adopt mobile commerce requires decision model that does just that. The purpose of the present study is to address these issues; we develop a hybrid MCDM model that combines DEMATEL, DANP, and VIKOR. The hybrid method overcome the limitations of existing decision models and can be used to help us analyze the criteria that influence b2b m-commerce issue. In particular, we use Taiwan's SMEs as an example to study the interdependence among the factors that influence the adoption of b2b m-commerce in the SMEs as well as evaluate alternative adoption processes to achieve the aspired levels of performance from $b 2 b$ m-commerce.

\section{Methodology}

This Section comprises four parts: the first part presents the DEMATEL technique for building an influential network relationship; the second part calculates the influential weights using DANP (DEMATEL-based ANP); the third, the last part uses VIKOR to evaluate total accreditation performance; finally, describes the data collection.

\subsection{DEMATEL for establishing an influential network relationship}

DEMATEL is mainly used to solve complex problems to clarify their essential nature. DEMATEL uses matrix and related mathematical theories (Boolean operation) to calculate the cause and effect relationships involved in each element. This technique is widely used to solve various complex studies, and particularly to understand complex problem structures and provide viable problem-solving methods (Tzeng et al., 2007). DEMATEL is based on the concept of influential relationship map, which can distinguish the direct/indirect influential relationship of the criteria; allowing decision-makers to identify the key criterion for developing strategies for improving b2b m-commerce in SMEs of this study (see the appendix).

\subsection{Find the influential weights using the DANP}

This study not only uses the DEMATEL technique to confirm the interactive relationship among the various dimensions/criteria, but also seeks the most accurate influential weights. This study found that ANP can serve this purpose. This study used the basic concept of ANP (Saaty, 1996), which eliminates the limitations of Analytic Hierarchy Process (AHP) and is applied to solve nonlinear and complex network relations (Saaty, 1996). ANP is intended to solve interdependence and feedback problems of criteria. This study thus applies the characteristics of influential weights ANP and combines them with DEMATEL (call DANP, DEMATEL-based ANP) to solve these kind of problems based on the basic concept of ANP. This approach yields more practical results (see the appendix). 


\subsection{Evaluating competitiveness gaps using VIKOR}

Opricovic and Tzeng (2004) proposed the compromise ranking method (VIKOR) as a suitable technique for implementation within MCDM (Tzeng et al., 2005; Opricovic and Tzeng, 2004; Opricovic and Tzeng, 2007; Liu and Tzeng, 2012). VIKOR uses the class distance function (Yu, 1973) based on the concept of the positive-ideal (or we adopt the Aspiration level) solution and Negative-ideal (or we adopt the Worst level) solution and puts the results in order. For normalized class distance function it is better to be near the positive-ideal point (the aspiration level) and far from the negative-ideal point (the worst value) for normalized class distance function (see the appendix).

\subsection{Data Collection}

Table 1 descripts the framework of dimensions and criteria. And the data was collected from 30 knowledge experts who understand mobile commerce trend and usage in SEMs (in consensus, significant confidence is $99.918 \%$, more than $95 \%$; i.e., gap error $=0.082 \%$, smaller less $5 \%$ ). Most of the education experts have teaches more than ten years in higher education. Expert perspectives on all criteria within the criteria were collected via personal interviews and a questionnaire. Expert elicitation was conducted in Jan., 2013, and it took 60 to 70 minutes for each subject to complete a survey.

Table 1: Framework of dimensions and criteria

\begin{tabular}{llll}
\hline Dimensions & Criteria \\
\hline$D_{1}$ & Technology context & $C_{1}$ & Technology readiness \\
& & $C_{2}$ & Technology integration \\
& & $C_{3}$ & Technology competence \\
$D_{2}$ & Organization context & $C_{4}$ & Top management emphasis \\
& & $C_{5}$ & Employees' IS knowledge \\
& & $C_{6}$ & Firm size \\
$D_{3}$ & Environment context & $C_{7}$ & Competitive pressure \\
& & $C_{8}$ & Partner support \\
& $C_{9}$ & Regulatory environment \\
\hline
\end{tabular}

\section{Empirical study for b2b m-commerce in SMEs issue}

In this section, an empirical study is displayed to illustrate the application of the proposed model for evaluating and selecting the best method that can help decision makers to understand how to improve their evaluations of $\mathrm{b} 2 \mathrm{~b} \mathrm{~m}$-commerce issue.

\subsection{Analysis of Result}

In this paper, we confirmed DEMATEL decision-making structure, and analyzed from three dimensions with 9 criteria of the TOE framework perspective on b2b mobile commerce. According to the expert questionnaires, we obtain the total influence matrix $\boldsymbol{T}$ of dimensions and criteria shown in Table 2 to Table 3. We find the cognition and opinion from experts in three dimensions, and the relationship between the extents of the impact can also be found which is compared to other dimensions as show in Table 2.

Table 2: Total influential matrix of $\boldsymbol{T}$ and the sum of the effects on the dimensions

\begin{tabular}{lccccccc}
\hline Dimensions & $D_{1}$ & $D_{2}$ & $D_{3}$ & $d_{i}$ & $s_{i}$ & $d_{i}+s_{i}$ & $d_{i}-s_{i}$ \\
\hline Technology context & 0.404 & 0.372 & 0.376 & 1.152 & 1.264 & 2.416 & -0.112 \\
Organization context & 0.472 & 0.379 & 0.406 & 1.257 & 1.095 & 2.352 & 0.162 \\
Environment context & 0.389 & 0.344 & 0.325 & 1.058 & 1.108 & 2.166 & -0.050 \\
\hline
\end{tabular}


According to the total influence prominence $\left(d_{i}+s_{i}\right)$, "technology context $\left(D_{1}\right)$ " has the highest influence of the strength of relationship that means the most important influencing dimensions; in addition, "environment context $\left(D_{3}\right)$ " is all the factors that affect the least degree of other dimensions. According to the influence relationship $\left(d_{i}-s_{i}\right)$, we can also find "organization context $\left(D_{2}\right)$ " is the highest degree of influence relationship that affects other dimensions directly. Otherwise, "technology context $\left(D_{1}\right)$ " is the most vulnerable to influence that compare with other dimensions. According to Table 3, we can obtain all the criteria of the impact of relations with each criterion. And then, from Table 4 shows the relationship between the extents of the direct or indirect influences and compares them with other criteria. "Top management emphasis $\left(C_{4}\right)$ " is the most important considerations criteria; in addition, "competitive pressure $\left(C_{7}\right)$ " is the influence of all criteria in the least degree of other criteria. Furthermore, we can also find in Table 4 that shows "competitive pressure $\left(C_{7}\right)$ " is the highest degree of influence relationship in all the criteria. And, "technology readiness $\left(C_{1}\right)$ ", is the most vulnerable to impact of criteria that compare with other criteria.

We use DEMATEL to confirm the influence relationship with the criteria, and expect to obtain the most accurate influence weights. The purpose of DANP is to solve the interdependence and feedback problems of each criterion (Saaty, 1996). Therefore, we structure the quality assessment model by DEMATEL which combination with DANP model to obtain the influential weight of each criterion as show in Table 4.

Table 3: The sum of influences, weights and rankings of each criterion

\begin{tabular}{clcccc}
\hline Dimensions/Criteria & $d_{i}$ & $s_{i}$ & $d_{i}+s_{i}$ & $d_{i}-s_{i}$ \\
\hline$D_{1}$ & Technology context & & & & \\
$C_{1}$ & Technology readiness & 1.175 & 1.279 & 2.454 & -0.104 \\
$C_{2}$ & Technology integration & 1.298 & 1.213 & 2.511 & 0.085 \\
$C_{3}$ & Technology competence & 1.160 & 1.142 & 2.302 & 0.019 \\
$D_{2}$ & Organization context & & & & \\
$C_{4}$ & Top management emphasis & 1.315 & 1.308 & 2.623 & 0.007 \\
$C_{5}$ & Employees' IS knowledge & 1.133 & 1.104 & 2.237 & 0.030 \\
$C_{6}$ & Firm size & 0.961 & 0.998 & 1.959 & -0.037 \\
$D_{3}$ & Environment context & & & & \\
$C_{7}$ & Competitive pressure & 1.080 & 2.081 & -0.079 & 1.080 \\
$C_{8}$ & Partner support & 0.972 & 1.992 & 0.049 & 0.972 \\
$C_{9}$ & Regulatory environment & 0.875 & 1.781 & 0.030 & 0.875 \\
\hline
\end{tabular}

In addition, we can find the critical criteria in SMEs of b2b mobile commerce adoption are identified as technology readiness $\left(C_{1}\right)$, technology integration $\left(C_{2}\right)$ and top management emphasis $\left(C_{4}\right)$. Furthermore, the influence weights combine with the DEMATEL technique to assess the priority of problem-solving based on the gaps identified by VIKOR method and the influence network relationship map.

An empirical study involving b2b m-commerce adoption in SMEs is used to evaluate and improve the total accreditation gaps using the VIKOR method, as listed in Table 4. Decision makers can identify problem-solving issues according to this integrated index, either from the perspective of the criteria as a whole or from that of an individual dimension.

Using the overall/dimension criteria, the gap values can be determined by the priority sequence improvement for reaching the desired level. In b2b m-commerce adoption, employees' IS knowledge $\left(C_{5}\right)$, with a higher gap value of 0.366 , are the first criterion to be improved. 
Improvement priority can also be applied to the individual dimension. In the technology context $\left(D_{1}\right)$, for instance, the priority gap values are ordered as follows: technology competence $\left(C_{3}\right)$, technology integration $\left(C_{2}\right)$, technology readiness $\left(C_{1}\right)$. In the perceived organization context $\left(D_{2}\right)$, the priority gap values are ordered as follows: employees' IS knowledge $\left(C_{5}\right)$, Top management emphasis $\left(C_{6}\right)$, management emphasis $\left(C_{4}\right)$. In the environment context $\left(D_{3}\right)$, the improvement priorities can be sequenced as follows: partner support $\left(C_{8}\right)$, regulatory environment $\left(C_{9}\right)$, competitive pressure $\left(C_{7}\right)$. Using the gap values provided by the panel experts above, improvement priority schemes are unique and comprehensive, both from the separate dimensions and from the overall points of view, as shown in Table 4.

For decision makers, understanding improvement priorities of $\mathrm{b} 2 \mathrm{~b}$ m-commerce adoption for client must be easier to understand than the gaps in SMEs.

Table 4 The gap evaluation of b2b mobile commerce by VIKOR

\begin{tabular}{|c|c|c|c|c|}
\hline & Dimensions/ Criteria & Local Weight & $\begin{array}{r}\text { Global weight } \\
\text { (DANP) }\end{array}$ & B2b-commerce gap $\left(r_{k j}\right)$ \\
\hline$D_{1}$ & Technology context & $0.364(1)$ & & 0.194 \\
\hline$C_{1}$ & Technology readiness & 0.350 & 0.127 & 0.113 \\
\hline$C_{2}$ & Technology integration & 0.338 & 0.123 & 0.213 \\
\hline$C_{3}$ & Technology competence & 0.313 & 0.114 & 0.266 \\
\hline$D_{2}$ & Organization context & $0.317(3)$ & & 0.292 \\
\hline$C_{4}$ & Top management emphasis & 0.381 & 0.121 & 0.228 \\
\hline$C_{5}$ & Employees' IS knowledge & 0.330 & 0.105 & 0.366 \\
\hline$C_{6}$ & Firm size & 0.289 & 0.091 & 0.294 \\
\hline$D_{3}$ & Environment context & $0.319(2)$ & & 0.295 \\
\hline$C_{7}$ & Competitive pressure & 0.366 & 0.117 & 0.266 \\
\hline$C_{8}$ & Partner support & 0.335 & 0.107 & 0.338 \\
\hline$C_{9}$ & Regulatory environment & 0.299 & 0.096 & 0.284 \\
\hline & $S A_{1}$ & \multicolumn{2}{|c|}{ Total gaps } & 0.258 \\
\hline
\end{tabular}

\subsection{Discussions and implications}

The empirical results are discussed as follows. First, according to the DEMATEL model, we could recognize the interrelationship of each dimension and criterion the influential relationship network map for each dimension and criterion (as Fig. 1 shows). In Fig. 1, the organization context $\left(D_{2}\right)$ is affecting other dimensions- environment context $\left(D_{3}\right)$, and, technology context $\left(D_{1}\right)$; visibly organization context $\left(D_{2}\right)$ plays an important role and it has the highest and intensity influence in its relationship to other dimensions. Thus, SMEs leader should first improve it, then, followed by environment context $\left(D_{3}\right)$, technology context $\left(D_{1}\right)$ for evaluating and improving the b2b m-commerce adoption in SMEs.

Second, after analyzing the dimensions, we would illustrate the considered-criteria in each dimension. According to the results, we illustrate the influence relationship-digraph-map of criteria in Fig. 1. Hence, for the influence relationship of these criteria, in the technology context $\left(D_{1}\right)$ : technology integration $\left(C_{2}\right)$ was the most influence criterion and should be improved first, followed by technology competence $\left(C_{3}\right)$ and technology readiness $\left(C_{1}\right)$ (see Fig. 1 for more details on the causal relationship in $D_{1}, D_{2}$, and $D_{3}$ ). Each of the evaluation dimensions and criteria creates the necessary behaviors for inducing $\mathrm{b} 2 \mathrm{~b} \mathrm{~m}$ commerce adoption in SMEs. Therefore, SMEs leader should evaluate all of the dimensions and criteria for the $\mathrm{b} 2 \mathrm{~b}$ m-commerce in accordance with Fig. 1. This evaluation method can be used in most of the SMEs. However, SMEs leader should keep in mind that, when applying this model, some differences exist. The level of importance for the 9 criteria may vary according to the particulars of each company, 
and the SMEs leader should compare the evaluation methods for each $\mathrm{b} 2 \mathrm{~b}$ m-commerce model before making deciding upon the optimal using adoption method.

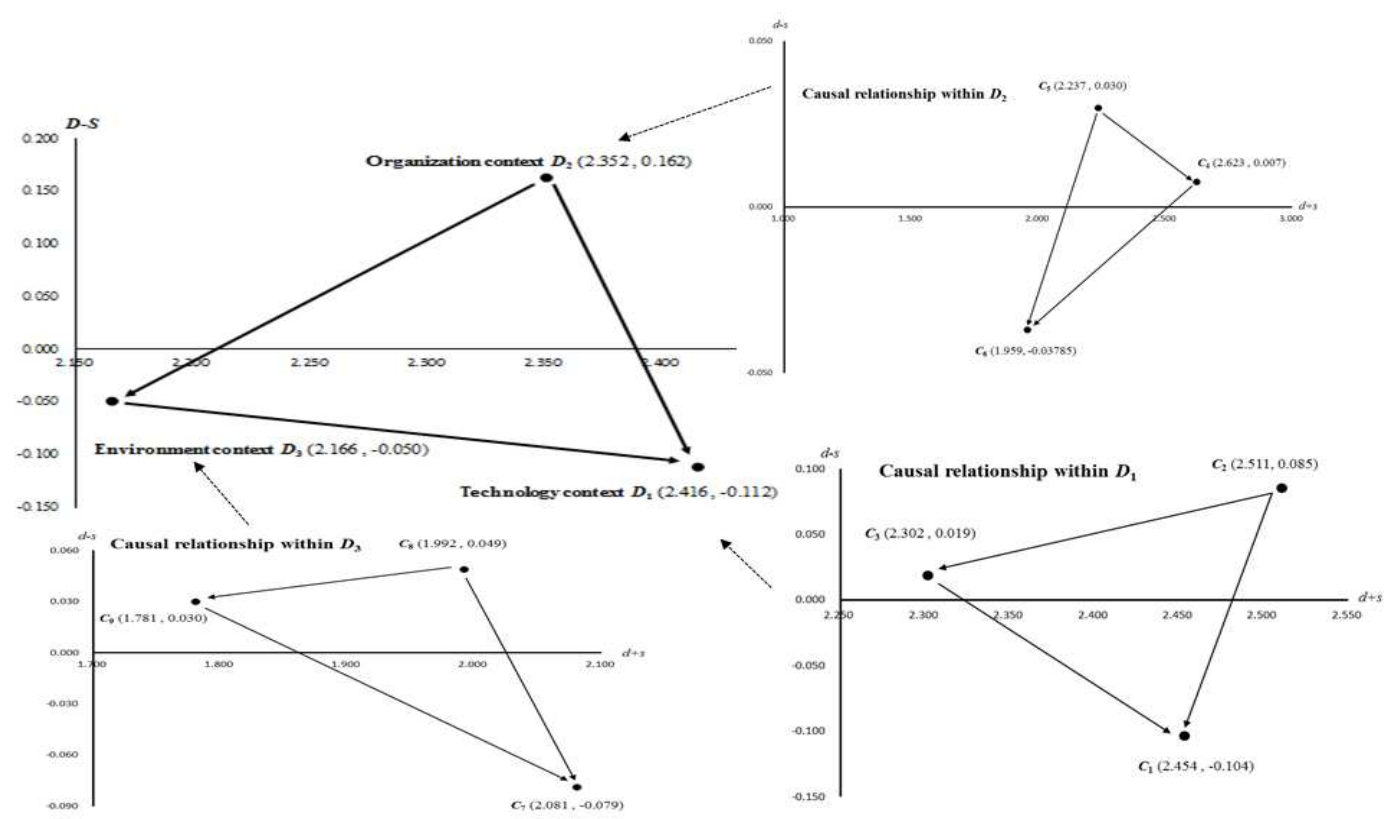

Figure 1: The influential network relationship map of each dimension and criterion

Finally, the overall gap values (i.e., the distance to 0 ) showed in Table 4 that indicate room for improvement is 0.258 for $\mathrm{b} 2 \mathrm{~b} \mathrm{~m}$-commerce adoption. In the TOE perspective, the environment context $\left(D_{3}\right)$, featuring the largest gap value of 0.295 , which should be the first priority for improvement if decision makers wish to achieve the desired level. For long-term improvement, the decision makers should manage internal motivation carefully, as mentioned above. Given these empirical findings, our results, as holistically formulated in Table 5, fulfill the purpose of this research. Evaluating the b2b mcommerce adoption model provided by this study can extend to most SMEs using b2b m-commerce adoption decision. However, SMEs administrators should be cautious when applying this model. The importance of the 9 criteria may vary according to the situation, and administrators should compare the b2b m-commerce adoption and define the gap before making decision on optimal technology use.

Table 5: Sequence of improvement priority for b2b m-commerce adoption

\begin{tabular}{ll}
\hline Formula & Sequence of improvement priority \\
\hline F1: Influential network of dimensions & $\left(D_{2}\right),\left(D_{3}\right),\left(D_{1}\right)$ \\
$\begin{array}{l}\text { F2: Influential network of criteria within } \\
\text { individual dimensions }\end{array}$ & $\left(D_{1}\right):\left(C_{2}\right),\left(C_{3}\right),\left(C_{1}\right)$ \\
& $\left(D_{2}\right):\left(C_{5}\right),\left(C_{4}\right),\left(C_{6}\right)$ \\
& $\left(D_{3}\right):\left(C_{9}\right),\left(C_{8}\right),\left(C_{7}\right)$ \\
& \\
F3:Sequence of dimension to rise to & $\left(D_{3}\right),\left(D_{2}\right),\left(D_{1}\right)$ \\
$\quad \begin{array}{l}\text { aspired/desired level (by gap value, from } \\
\text { high to low) }\end{array}$ & $\left(D_{1}\right):\left(C_{3}\right),\left(C_{2}\right),\left(C_{1}\right)$ \\
$\begin{array}{l}\text { F4:Sequence of criteria to rise to } \\
\text { aspired/desired level within individual } \\
\text { dimension (by gap value, from high to low) }\end{array}$ & $\left(D_{2}\right):\left(C_{5}\right),\left(C_{6}\right),\left(C_{4}\right)$ \\
& $\left(D_{3}\right):\left(C_{8}\right),\left(C_{9}\right),\left(C_{7}\right)$ \\
\hline
\end{tabular}




\section{Conclusion}

Mobile commerce has an important role in the SMEs. Its decisions are complicated by the fact that various criteria are uncertainty and may vary across the different product categories and use situations. Based on the export and literature review, we developed the three dimensions and 9 criteria that align with the b2b mobile commerce of environment. So we applied the methodology of hybrid MCDM model combining DANP with VIKOR in empirical case. The main reason is among the numerous approaches that are available for conflict management, hybrid MCDM is one of the most prevalent. VIKOR is a method within MCDM; it is based on an aggregating function representing closeness to the ideal (aspiration level), which can be viewed as a derivative of compromise programming for avoiding "choose the best among inferior alternatives (i.e., pick the best apple among a barrel of rotten apples)". In a decision-making process, we used the global and local weights into alternatives performance, such as that in Table 5, to allow firm's leader to evaluate the b2b mobile commerce factor. We haven't only selected the best factor, but also found how to improve the gaps to achieve the aspiration level in mobile commerce service performances.

\section{REFERENCES}

Liu, J.J.H., \& Tzeng, G,H. (2012). Comments on "Multiple criteria decision making (MCDM) methods in economics: an overview. Technological and Economic Development of Economy, 18(4), 672-695.

Opricovic, S., \& Tzeng, G.H. (2004). Compromise solution by MCDM methods: A comparative analysis of VIKOR and TOPSIS. European Journal of Operational Research, 156(2), 445-455.

Opricovic, S., \& Tzeng, G.H. (2007). Extended VIKOR method in comparison with outranking methods. European Journal of Research, 178(2), 514-529.

Saaty, T.L. (1996). Decision Making with Dependence and Feedback: Analytic Network Process, RWS Publications, Pittsburgh, New York.

Tzeng, G.H., Tsaur, S.H., Laiw, Y.D., \& Opricovic, S. (2002a). Multicriteria analysis of environmental quality in Taipei: Public preferences and improvement strategies. Journal of Environmental Management, 65(2), 109-120.

Tzeng, G.H., Teng, M.H., Chen, J.J., \& Opricovic, S. (2002b). Multicriteria selection for a restaurant location in Taipei. International Journal of Hospitality Management, 21(2), 171-187.

Tzeng, G.H., Lin, C.W., \& Opricovic S. (2005). Multi-criteria analysis of alternative-fuel buses for public transportation. Energy Policy, 33(11), 1373-1383.

\section{APPENDIX: A HYBRID MCDM MODEL COMBINED WITH DEMATEL, DANP, AND VIKOR}

DEMATEL is used to build the influential relationship matrix for dimensions/criteria to measure the cause and effect on each element. The DEMATEL technique contains three steps.

Step 1: Find the average influence matrix $Z$

The first step is to calculate initial matrix, using pair of degree of interaction/interrelationship to obtain directly influence matrix $Z=\left[z_{i j}\right]_{n \times n}$, where represents the degree of effect on $i$ factor effects $j$ factor (Lin \& Tzeng, 2009; Chen et al., 2010). 


$$
\boldsymbol{Z}=\left[z_{i j}\right]_{n \times n}=\frac{1}{K} \sum_{k=1}^{K}\left[z_{i j}\right]_{n \times n}
$$

Step 2: Calculate the normalized influence matrix $D$

When the elements of $i$ have a direct effect on the elements of $j$, then, otherwise. The second step is to normalize the matrix. It can be obtained from Eq. (2) and (3). Its diagonal is 0 , and maximum sum of row or column is 1 .

$$
\begin{aligned}
& \boldsymbol{D}=s \boldsymbol{Z} \\
& s=\min _{i, j}\left\{\frac{1}{\max _{i} \sum_{j=1}^{n}\left|z_{i j}\right|}, \frac{1}{\max _{j} \sum_{i=1}^{n}\left|z_{i j}\right|}\right\}, i, j=1,2, \ldots, n
\end{aligned}
$$

Step 3: Compute the total influence matrix $T$

The total-influence matrix $\boldsymbol{T}$ can be obtained through Eq. (4), in which $\boldsymbol{I}$ denotes the identity matrix. $\boldsymbol{T}=\boldsymbol{A}+\boldsymbol{A}^{2}+\cdots+\boldsymbol{A}^{h}=\boldsymbol{A}(\boldsymbol{I}-\boldsymbol{A})^{-1}$ when $\lim _{h \rightarrow \infty} \boldsymbol{A}^{h}=[0]_{n \times n}$

To sum of each row and column of the total effect matrix $\boldsymbol{T}=\left[t_{i j}\right]$. It will obtain the sum of all rows (vector $\left.\quad \boldsymbol{d}=\left[d_{i}\right]_{n \times 1}=\left[\sum_{j=1}^{n} t_{i j}\right]_{n \times 1}=\left(d_{1}, \ldots, d_{i}, \ldots, d_{n}\right)^{\prime}\right)$ and the sum of all columns (vector $\left.\boldsymbol{s}=\left[s_{j}\right]_{1 \times n}^{\prime}=\left[\sum_{i=1}^{n} t_{i j}\right]_{1 \times n}^{\prime}=\left(s_{1}, \ldots, s_{j}, \ldots, s_{n}\right)^{\prime}\right)$. If $d_{i}$ represents the sum of all rows of the total-influence matrix $\boldsymbol{T}$, meaning directly or/and indirectly affects to other criteria; $s_{j}$ represents the sum of all columns of the total-influence matrix $\boldsymbol{T}$, meaning is affected by other criteria. $d_{i}$ represents the factor which will affect other factors, $s_{j}$ represents the factor that is affected by other factors. According to the definition, $d_{i}+s_{j}$ presents the degree of relationship between the factors, meaning "prominence"; $d_{i}-s_{j}$ presents the degree of effect and effected for the factors, meaning "relation" (Tzeng et al., 2007).

DANP is divided into following steps:

Step 1: Develop the structure of the question

The questions are clearly described then break them down to level structure.

Step 2: Develop Unweighted Supermatrix

Firstly, each level with total degree of effect that obtains from the total-influence matrix $\boldsymbol{T}$ of DEMATEL as shown in Eq. (5).

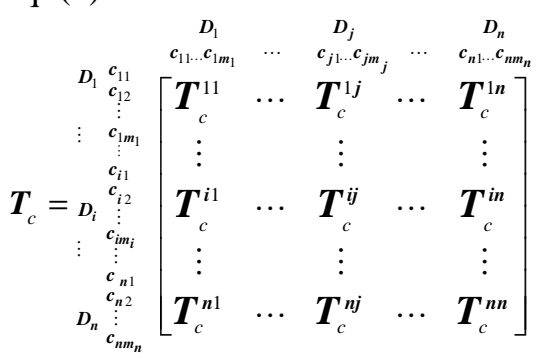

Normalize $\boldsymbol{T}_{c}$ with total-influence will be obtained $\boldsymbol{T}_{c}^{\alpha}$ that shows in Eq. (6).

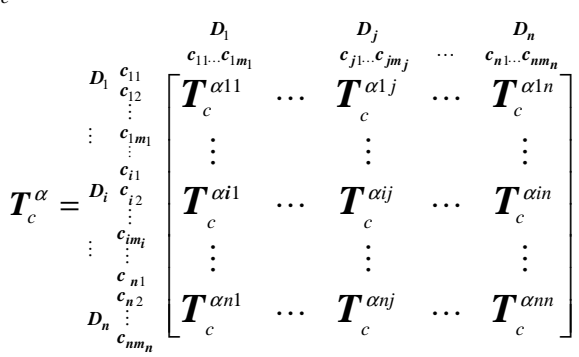

Normalize $\boldsymbol{T}_{c}^{\alpha 11}$ will be obtained by Eqs. (7) and (8), according to the same fashion will be obtained $\boldsymbol{T}_{c}^{\alpha n n}$.

$$
d_{i}^{11}=\sum_{j=1}^{m_{1}} t_{c i j}^{11}, i=1,2, \ldots, m_{1}
$$




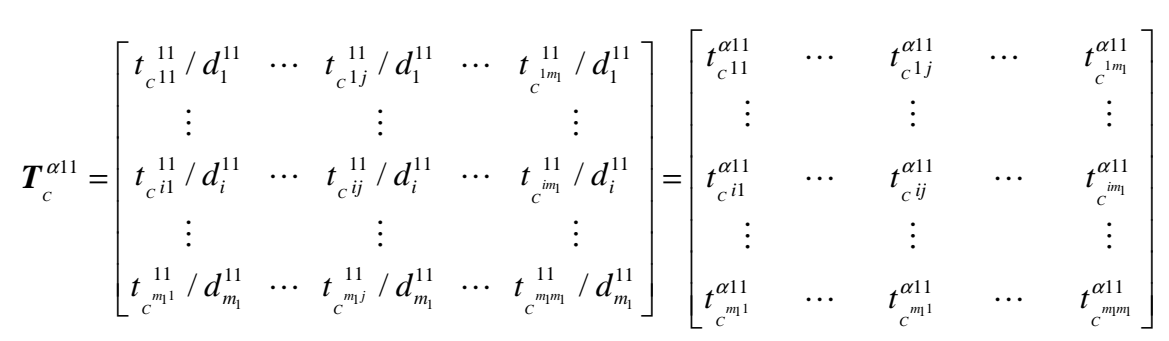

And then, total-influence matrix is normalized into Supermatrix according to the group in relying relationship to obtain Unweighted Supermatrix as show in Eq. (9).

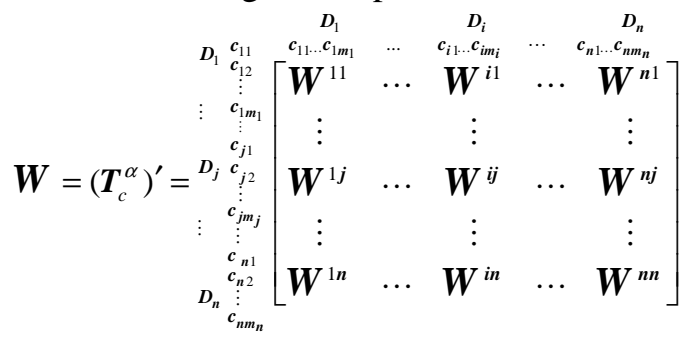

In addition, we will be obtained matrix $W^{11}$ and $W^{12}$ by Eq. (10). If blank or 0 shown in the matrix means the group or criteria is independent, according to the same fashion will be obtained matrix $W^{n n}$.

Step 3: Obtain Weight Supermatrix

Let each dimension of total-influence matrix $\boldsymbol{T}_{D}$ as (11) be normalized with total degree of influence to obtain $\boldsymbol{T}_{D}^{\alpha}$, the result as Eq. (12).

$d_{i}=\sum_{j=1}^{n} t_{D}^{i j}, i=1,2, \ldots, n$ and $t_{D}^{\alpha i j}=t_{D}^{i j} / d_{i}, i=1,2, \ldots, n$

$$
\begin{aligned}
\boldsymbol{T}_{D} & =\left[\begin{array}{ccccc}
t_{D}^{11} & \cdots & t_{D}^{1 j} & \cdots & t_{D}^{1 n} \\
\vdots & & \vdots & & \vdots \\
t_{D}^{i 1} & \cdots & t^{i j} & \cdots & t_{D}^{i n} \\
\vdots & & \vdots & & \vdots \\
t_{D}^{n 1} & \cdots & t^{n j} & \cdots & t_{D}^{n n}
\end{array}\right] \\
\boldsymbol{T}_{D}^{\alpha} & =\left[\begin{array}{ccccc}
t_{D}^{11} / d_{1} & \cdots & t_{D}^{1 j} / d_{1} & \cdots & t_{D}^{1 n} / d_{1} \\
\vdots & & \vdots & & \vdots \\
t_{D}^{i 1} / d_{i} & \cdots & t_{D}^{i j} / d_{i} & \cdots & t_{D}^{i n} / d_{i} \\
\vdots & & \vdots & & \vdots \\
t_{D}^{n 1} / d_{n} & \cdots & t_{D}^{n j} / d_{n} & \cdots & t_{D}^{n n} / d_{n}
\end{array}\right]=\left[\begin{array}{ccccc}
t_{D}^{\alpha 11} & \cdots & t_{D}^{\alpha 1 j} & \cdots & t_{D}^{\alpha 1 n} \\
\vdots & & \vdots & & \vdots \\
t_{D}^{\alpha i 1} & \cdots & t_{D}^{\alpha i j} & \cdots & t_{D}^{\alpha i n} \\
\vdots & & \vdots & & \vdots \\
t^{\alpha n 1} & \cdots & t_{D}^{\alpha n j} & \cdots & t_{D}^{\alpha n n}
\end{array}\right]
\end{aligned}
$$

Then, drive the normalized $\boldsymbol{T}_{D}^{\alpha}$ into Unweight Supermatrix $\boldsymbol{W}$ to obtain Weight Supermatrix $\boldsymbol{W}^{\alpha}$, the result as shown in Eq. (13).

$$
\boldsymbol{W}^{\alpha}=\boldsymbol{T}_{D}^{\alpha} \boldsymbol{W}=\left[\begin{array}{ccccc}
t_{D}^{\alpha 11} \times \boldsymbol{W}^{11} & \cdots & t_{D}^{\alpha i 1} \times \boldsymbol{W}^{i 1} & \cdots & t_{D}^{\alpha n 1} \times \boldsymbol{W}^{n 1} \\
\vdots & & \vdots & & \vdots \\
t_{D}^{\alpha 1 j} \times \boldsymbol{W}^{1 j} & \cdots & t_{D}^{\alpha i j} \times \boldsymbol{W}^{i j} & \cdots & t_{D}^{\alpha n j} \times \boldsymbol{W}^{n j} \\
\vdots & & \vdots & & \vdots \\
t_{D}^{\alpha 1 n} \times \boldsymbol{W}^{1 n} & \cdots & t_{D}^{\alpha i n} \times \boldsymbol{W}^{i n} & \cdots & t_{D}^{\alpha n n} \times \boldsymbol{W}^{n n}
\end{array}\right]
$$

Step 4: Obtain limit supermatrix

According to the weighted spuermatrix $W^{\alpha}$, it multiplies by itself multiple times to obtain limit supermatrix. Then, the ANP weights of each criterion can be obtained by $\lim _{g \rightarrow \infty}\left(\mathbf{W}^{\alpha}\right)^{g}$, where $g$ represents any number for power. 


\section{VIKOR can be divided into follow steps:}

Step 1: Check the best value $f_{j}^{*}$ and the worse value $f_{j}^{-}$

There $f_{j}^{*}$ represents the positive-ideal point, that means the expert gives the scores of the best value (aspired levels) in each criterion and $f_{j}^{-}$represents the negative-ideal point, that means the expert gives the scores of the worst values in each criterion. We use Eqs. (14) and (15) to obtain the results.

$f_{j}^{*}=\max _{k} f_{k j}, j=1,2, \ldots, n$, (traditional approach)

or setting the aspired levels, vector $f^{*}=\left(f_{1}^{*}, f_{2}^{*}, \cdots, f_{n}^{*}\right)$

$f_{j}^{-}=\min _{k} f_{k j}, j=1,2, \ldots, n$ (traditional approach) $\square$

or setting the worst values, vector $f^{-}=\left(f_{1}^{-}, f_{2}^{-}, \cdots, f_{n}^{-}\right)$

Step 2: Calculate the mean of group utility and maximal regret $Q_{k}$.

There $S_{k}$ represents the ratios of distance to the positive-ideal, it means the synthesized gap for all criteria; $W_{j}$ represents the influential weights of the criteria from DANP; $r_{k j}$ represents the average gap-ratios (regret) of normalized distance to the aspired level point, and represents the maximal gap-ratios (regret) of normalized distance to the aspired level in all criteria, it means the maximal gap in criteria for prior improvement. Those values can be computed respectively by Eqs. (16) and (17).

$$
\begin{aligned}
& L_{k}^{p=1}=S_{k}=\sum_{j=1}^{n} w_{j} r_{k j}=\sum_{j=1}^{n} w_{j}\left(\left|f_{j}^{*}-f_{k j}\right|\right) /\left(\left|f_{j}^{*}-f_{j}^{-}\right|\right) \\
& L_{k}^{p=\infty}=Q_{k}=\max _{j}\left\{r_{k j} \mid j=1,2, \ldots, n\right\}
\end{aligned}
$$

Step 3: Obtain the comprehensive indicator $R_{k}$ and sorting results. The values can be computed respectively by Eq. (18).

$$
R_{k}=v\left(S_{k}-S^{*}\right) /\left(S^{-}-S^{*}\right)+(1-v)\left(Q_{k}-Q^{*}\right) /\left(Q^{-}-Q^{*}\right)
$$

Those values derived from $s^{*}=\min _{k} S_{k}$ or setting $S^{*}=0$ (the aspired level), $s^{-}=\max _{k} S_{k}$ or setting $S^{-}=1$ (the worst situation); $Q^{*}=\min _{k} Q_{k}$ or setting $Q^{*}=0$ (the aspired level), and $Q^{-}=\max _{k} Q_{k}$ or setting $Q^{-}=1$ (the worst situation). Therefore, when $s^{*}=0$ and $S^{-}=1, Q^{*}=0$ and $Q^{-}=1$ we can re-write the Eq.(18) as $R_{k}=v S_{k}+(1-v) Q_{k}$. Weight $v=1$ represents only to be consider the average gap (average regret) weight and weight $v=0$ represents only to be consider the max gap to be prior improvement. It can provide the decision-makers by experts. Generally $v=0.5$ (the majority of criteria), it could be adjusted depends on the situation. 